\title{
Nonlinear educational process
}

\author{
Evgeny Grigoriev*, Azat Valeev, and Shagit Musin
}

Sibay Institute (branch) of Bashkir State University, Faculty of Education, Sibay, Russia

\begin{abstract}
The article describes the features of organizing a competently oriented educational process of the university, showing its strengths and weaknesses. The features of nonlinear management of educational organizations and nonlinear construction of the educational process are described. Higher education development in Russia is proposed. The importance of the personality of students, the importance of the formation of professionally significant personality traits is indicated. The data of the survey (attitude of students to the existing educational process) of graduate students and their analysis are presented. New directions and conditions for the organization of a nonlinear educational process at the university are considered - blended learning using the traditional form of work (face to face), electronic and distance technologies, electronic information educational environment, modular structuring of educational material, etc.
\end{abstract}

\section{Introduction}

Currently, the educational process of higher school in our country is being implemented within the framework of the competence-oriented paradigm. This is a fairly new model for us. It has a number of advantages over the knowledge-centric paradigm, but it also has disadvantages. In recent decades, the world has been developing very rapidly, information very quickly becomes obsolete, new technologies appear. It is an indisputable fact that education has to adjust to this rapid pace. The systematic emergence of new educational standards, their updating and addition is not a solution to the problem.

Over the past 20-25 years, Russian higher education has been going through hard times. The processes of its reforming, the transition to the Unified State Exam, the fulfillment of the requirements of the Bologna Convention, modernization and optimization are constantly replacing each other. Not having time to complete any result, each of these processes is replaced by the next, also unsuccessful. According to a number of studies, there is dissatisfaction in the country with the state of affairs in higher education [1].

The standards establish strict requirements for the implementation of educational programs, focus on the list of competencies. A contradiction arises between the fact that the world is rapidly developing, confronts the future specialist with situations of uncertainty in the forthcoming professional activity, and educational standards strictly regulate the implementation of educational programs, offer unified ways of training specialists. Standardization limits, excludes the flexibility of the educational process. The proposed fixed «elective courses» restrict the development of both teachers and students. The author's courses are important, built taking into account the realities of future professional activities, including courses for practitioners.

\footnotetext{
* Corresponding author: gevgeniyn@ mail.ru
} 
A feature of the competence-oriented educational process is the training of a «functional specialist». Considering competence as a set of competencies - the ability to effectively fulfill the forthcoming professional activity, there is an emphasis on the functional component, the personal formation of the student comes to the background. This is also influenced by digitalization in all areas, the active introduction of e-learning and distance learning. Of course, modern computer systems allow the organization of the learning process in a distance format, but this does not allow to shape the personality (upbringing) of students. Electronic and distance courses are designed with a focus on a certain result (the formation of competence, the topic of the discipline, etc.). As a result of the successful mastering of such a course, the student will form certain abilities, competencies, but the formation of his personal qualities occurs unsystematically, in a non-targeted manner. The learner as a «person» goes by the wayside.

We can say that the existing linear educational process is focused on the step-by-step development of blocks of topics of academic disciplines, filling the student with information, shaping behavior and activities. In modern conditions, this is not effective. Taking into account the requirements of the Ministry of Education and Science of the Russian Federation, universities are placed in conditions of a budget deficit (the possibility of creating unprofitable groups is excluded, the ratio is $1 / 12$ ), this unifies the construction of educational trajectories. Under these conditions, students get used to working according to the algorithm, they turn into «thoughtless» performers who depend entirely on the teacher. It all comes down to mastering the fundamental theory of the discipline, with its subsequent transfer to the teacher, in order to get a good grade. Project activities are often absent. This greatly affects the creativity of students, their ability to make decisions on their own is worse. The educational process is inherently nonlinear, but until now there was no tools for implementing this. Today, the electronic information educational environment allows you to achieve the desired results - to build individual trajectories of students' development, automate the cut of progress and scoring, provide the opportunity for synchronous and asynchronous interaction, individual consultations at a distance. But at the same time, the informatization of the educational process gives rise to certain difficulties, this must be taken into account. Students get used to communicating with the teacher through computer programs (chats, e-mail, zoom, etc.), become self-absorbed, closed, their main communication outside the educational process takes place on social networks. This leads to psychological discomfort, students lose the habit of communicating in reality, to work together in teams.

Modular structuring of educational material becomes important. Firstly, modern professional activity is based on the intersection of disciplines, professions, complex manifestation of competencies (soft and hard). Secondly, the formation of competencies within the classroom-lesson system within the framework of autonomous disciplines does not give the expected result. Perhaps structuring the training material into modules with subsequent project activities will be more productive, but this requires serious changes in the educational process. Hypothetically, the study of modules in different universities with the subsequent transfer of the results will increase the quality of the educational process, the responsibility of teachers for the declared educational material. This will give rise to competition, students will have the opportunity to choose - in which university, with which teacher to study this or that module.

Deep differentiation of higher education is a global trend. The well-known American specialist in this field G. Rozovsky, characterizing the system of universities in the United States, which is considered the most developed in the world, writes: «The label «American universities» turns out to be practically meaningless if we remember that there are more than 4 thousand universities in the country, and among them there are those that can really cause general envy, and those that are not much different from the upper secondary school, and even there is so much between these two poles» [2]. 
Institutional diversity in higher education is a subject of active discussion in the works of many authors [4]. They are united by a common attitude towards diversity within the higher education system as a healthy attribute that broadens student choices [6].

\section{Research methodology}

When studying the nonlinearity of the educational process of higher education, two main priority areas crystallize - the nonlinearity of educational systems as a whole and the nonlinearity of the educational process.

One of the most important problems of the concept of a nonlinear model of higher education in our country is understanding and taking into account its differentiation and complex structure. In this regard, at least two circumstances should be specially noted. The first is the presence of different types of educational organizations (national, federal, national research, flagship universities, academies, etc.) and typologies as scientific methods of their research $[10,3]$. The second is the regional features of the processes taking place in higher education [3]. There has already been an attempt to structure universities in our country, but until now there is no well-established generally accepted classification. The main program today is considered to be the program of strategic and academic leadership «Priority-2030».

The study of a nonlinear model of higher education is based on the theory of resource dependence, according to which organizations and systems not only depend on their environment, but are themselves capable of influencing it [5]. With regard to higher education institutions in the region, this means the importance of studying their capabilities to closely and fruitfully interact with the economy, science, social and cultural spheres. This is also indicated by the theory of stakeholders [9].

The efficiency and quality of training of future specialists will increase significantly if educational organizations will closely interact with organizations and enterprises of the region, orienting their graduates to work in them. In the learning process, the practical training of students will be as close as possible to a realistic model of the future professional activity. With such training, targeted training becomes important, which allows you to motivate and support students (additional resources: scholarships, grants, etc.). Consequently, the management of each educational organization should be differentiated, taking into account the territorial characteristics, the economy of the region, its specifics, existing organizations and enterprises. Only in this case it will be possible to speak of a nonlinear approach.

By the nature and method of management in systems of linear and nonlinear type. In the first case, we are dealing with authoritarian management of the subject-object type, within which the subject of management is the power structures in the higher education system and their representatives, the object of management is educational organizations (universities) and educational communities in them. In the second case (nonlinear model), the implementation of the principle of subject-subject management as interaction, cooperation in the scientific-pedagogical and educational process of its participants is assumed [8]. Recently, there has been a tendency to move away from authoritarian management systems, priority is given to project activities, teamwork. Subject-subject interaction is more effective, as it is focused primarily on the final effective result, non-standardized, constantly changing in situations of uncertainty offered by today's dynamic world.

The nonlinearity of the management of the educational organization affects the nonlinearity of the organization of the educational process. Linear, authoritarian management presupposes a unified attitude towards all educational institutions of higher education. Their specificity, the peculiarities of the region and territorial location are not taken into account. This is a formal approach, it creates good reporting on paper, and the real quality of training of specialists has questions. Equalization of approaches and requirements for metropolitan 
and regional universities complicates the implementation of educational programs in the regions, puts regional universities in a complex competition. Often regional universities cannot withstand it, this destroys education in the regions.

The educational process is inherently nonlinear. The mechanism for transferring knowledge, forming competencies is complex, it cannot be standardized and implemented according to one specific algorithm. Of course, not enough to place the student in the position of the subject of the educational process, necessary to activate the student's motivation for learning (to arouse his interest). Here the teacher plays a huge role. He must build the educational process in such a way that the student receives an impact on the entire multifaceted structure of the personality. The student is characterized by manifestation in three directions - thinking, feeling and acting, the educational process should be built like this. The priority areas for the development of education are: Lifelong Iearning; the pressure of time and competition for attention (attracting the attention of listeners in the process of implementing electronic and distance education, receiving and creating an emotional response in new conditions); the emergence of the concept of «Consumer» (education is positioned as a commercial service); competition for engagement (a huge number of offers for the student); super-teams and the ability to cooperate (teamwork is more efficient and productive); the tendency of transition to democratic forms (departure from the authoritarian system of management and organization of the educational process); blended learning (integrated use of tools, methods, forms (face to face, electronic and distance learning), etc.)); platform solutions (byte size (unified productive educational platforms); microlearning (highly specialized quantum learning, unified for all information and communication platforms, micro-volume of information, micro-skill for 3-5 minutes); knowledge management (collection, preservation and updating of the database knowledge); ability to negotiate (search for contacts and interaction with educational institutions, companies and organizations).

Considering training as the interconnection of two main components - education and upbringing, it should be noted that the educational process should form the student's competence and professionally significant personality traits. In the learning process, it is necessary to systematically stimulate the student's activity (the educational process must offer it). This activity should not be limited only to the assimilation of information, but should form competencies in their final form (the ability to manifest them in the process of work without adaptation) by passing them through the cognitive and emotional-sensory spheres. As Voloshin R.G. writes. emotions and feelings of a person are conditioned by social conditions of existence and have a personal character. Emotions are subjective experiences. Feelings have not only subjective, but also objective content. They are called by objects of personal value and are addressed to them. The quality of the experiences contained in feelings depends on the personal meaning and meaning that an object has for a person. Feelings are associated not only with the external perceived properties of the object, but also with the knowledge and concepts that a person has about it. Feelings are effective in nature, they either stimulate or inhibit the activity of a person. Emotions and feelings are peculiar states of the psyche that impose meaning on the life, activity, actions and behavior of a person. If emotional states determine mainly the external side of behavior and mental activity, then feelings affect the content and inner essence of experiences.

\section{Research results}

In order to identify the attitude of students to the existing educational process, to identify and analyze its quality, a survey was conducted. The survey took about 3,000 full-time students of graduate courses of the Federal State Budgetary Educational Institution of Higher Education «Bashkir State University» and its branches. Interesting data have been obtained. 
When asked about providing a choice of disciplines when drawing up the basic educational program, $52 \%$ of the respondents answered that they were not given such an opportunity, $33 \%$ answered that they had the right to choose, $15 \%$ found it difficult to answer the question.

When asked about the availability of information related to the educational process, $61 \%$ of the respondents believe that it is available, $27 \%$ say it is not available, $12 \%$ find it difficult to answer.

When asked about employment parallel with study, $49 \%$ answered that they work, $51 \%$ do not.

When asked about a change in opinion about the chosen specialty, the respondents answered - $10 \%$ were disappointed in the specialty, $7 \%$ chose it unconsciously, only in order to study on a budgetary basis, $13 \%$ believe that their outlook on life has changed, the chosen specialty is no longer for them suitable, $26 \%$ changed their opinion about the specialty because they presented it differently, $44 \%$ are satisfied with the choice, consider their choice to be correct.

When asked about plans of work in their specialty after graduation, students answered - 52\% are planning, $13 \%$ are not planning, $35 \%$ of graduates found it difficult to answer (fig. 1).

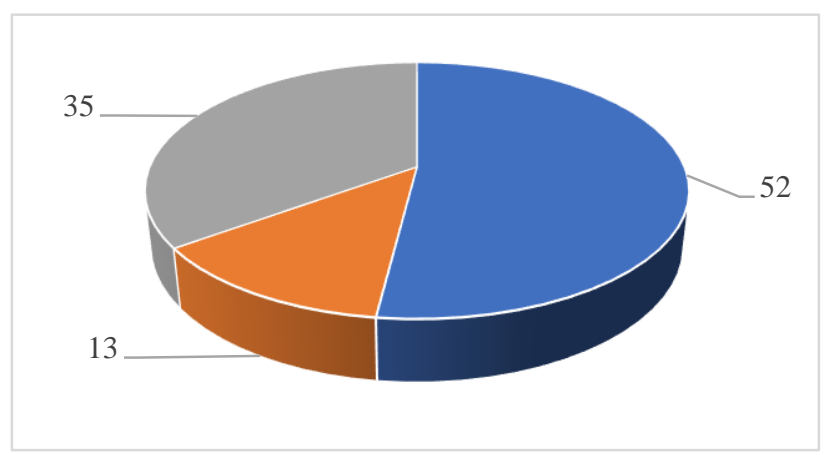

Fig. 1. Answers of students about the upcoming professional activity

\section{The discussion of the results.}

Analyzing the data obtained, one can assert. When forming the main educational program (students' choice of elective disciplines), students are given insufficient freedom to choose educational subjects. $52 \%$ of the respondents answered that they did not participate in this, $15 \%$ found it difficult to answer and only $33 \%$ confirmed the possibility of choice (participation in the formation of programs). This is a fairly low percentage, which speaks of the linearity and standardized learning process, the inability of students to influence the content of educational programs. Of course, this is facilitated by a number of subjective (many students in the learning process are not interested in the content of the programs, they choose elective courses superficially, do not associate the choice with subsequent professional activities, neglect the learning process as a whole, etc.) and objective reasons (teachers and employees of the organization in order to reduce paperwork, exclude the possibility of the appearance of small groups, they prefer to leave the curriculum unchanged).

As for the availability of information related to the educational process, $27 \%$ stated that it was not available, $12 \%$ of the respondents found it difficult to give an answer. The reason for this, perhaps, is the inability of students to independently navigate in large volumes of information (electronic libraries), in the absence of stable competencies necessary to work with an electronic information educational environment. 
The data of students' answers about parallel employment turned out to be interesting almost half of full-time students are working (49\%). This is undoubtedly good, it speaks about the responsibility of students, their consciousness. At the same time, not all students work in the field of their upcoming professional activities, which is not very effective in terms of economic development and the rationality of spending budget funds on education (the work of students, ideally, should be related to the direction of their education).

When answering the question about a change in opinion about the chosen specialty, only $44 \%$ are sure of the correctness of their choice, the remaining students, for one reason or another, consider it to be erroneous. This means that then students begin to work outside their specialty, experience difficulties in the process of performing a new, difficult for them (due to the fact that they studied to work in another field) professional activity. This affects the quality of personnel and the economy of the country as a whole. This is also confirmed by the students' answers to the question about employment after training. Only 52\% of graduates declare that they are going to work in their specialty - this is not enough.

\section{Conclusion}

Summing up, it should be noted. In the system of higher education, there is a tendency that many university graduates do not go to work in their specialty. This speaks of the unconscious choice by many students of the areas of training, of the linearity, standardization of the educational process, the presence of a "classical" component in it, focused on the mastery of the fundamental foundations of subjects by students, its isolation from the reality of the changing world. A fairly large number of students do not associate their studies with their future professional activities. Perhaps this is a consequence of the fact that the educational process is focused on functional training, the student's personality is not sufficiently formed. The modern model of management of educational organizations, like the educational process itself, is still not focused on nonlinearity, although today the necessary tools and conditions for this have appeared (computer systems, software, digitalization of society and the economy).

\section{References}

1. E.V. Balatsky, Journal of the New Economic Association , 4, 24 (2014)

2. G. Rozovsky, International higher education, 2(76), 8 (2014)

3. I.V. Abankina, F.T. Aleskerov, V.Yu. Belousova, L.M. Gokhberg, K. V. Zinkovsky, S.G. Kiselgof, S. V. Shvydun, Foresight-Russia, 3, 48 (2013)

4. J. Huisman, L. Meek, F. Wood, Higher Education Quarterly, 563 (2007)

5. J. Pfeffer, G.Salancik, The external control of organizations: A resource dependence perspective (2003)

6. O.V. Leshukov, M.A. Lisyutkin, University Management: Practice and Analysis, 6, 29 (2015)

7. P.A. David, Path dependence, its critics and the quest for historical economics. Market Failure or Success (All Souls College, Oxford and Stanford University, 2002)

8. Participation in the management of the university: scientific publication, 120 (2016)

9. R.E. Freeman, A. Moutchnik. . Uwf Umw, 21, 5 (2013)

10. Ya.I. Kuzminov, D.S. Semenov, I.D. Frumin, Russian Education \& Society, 4, 8(2013) 